\title{
International Prognostic Index Low Risk Group
}

National Cancer Institute

\section{Source}

National Cancer Institute. International Prognostic Index Low Risk Group. NCI Thesaurus. Code C161806.

A risk group associated with a total score of 0 or 1 on the International Prognostic Index indicating that an individual has a 5 year survival prognosis of $73 \%$. 